\title{
Partial Correlation Analysis of Association between Subjective Well-Being and Ecological Footprint
}

\author{
Jinting Zhang ${ }^{1}$, F. Benjamin Zhan ${ }^{2}$, Xiu $\mathrm{Wu}^{2, *}$ and Daojun Zhang ${ }^{3}$ (1) \\ 1 School of Resource and Environmental Science, Wuhan University, Wuhan 430079, China; \\ whuzjt@whu.edu.cn \\ 2 Department of Geography, Texas State University, San Marcos, TX 78666, USA; zhan@txstate.edu \\ 3 College of Economics and Management, Northwest A\&F University, Xianyang 712100, China; \\ cugzdj@gmail.com \\ * Correspondence: x_w10@txstate.edu; Tel.: +1-512-781-0041
}

\section{check for}

updates

Citation: Zhang, J.; Zhan, F.B.; Wu X.; Zhang, D. Partial Correlation Analysis of Association between Subjective Well-Being and Ecological Footprint. Sustainability 2021, 13, 1033. https://doi.org/10.3390/ su13031033

Received: 23 December 2020

Accepted: 15 January 2021

Published: 20 January 2021

Publisher's Note: MDPI stays neutral with regard to jurisdictional claims in published maps and institutional affiliations.

Copyright: (c) 2021 by the authors. Licensee MDPI, Basel, Switzerland. This article is an open access article distributed under the terms and conditions of the Creative Commons Attribution (CC BY) license (https:// creativecommons.org/licenses/by/ $4.0 /)$.

\begin{abstract}
A spatial-temporal panel dataset was collected from 101 countries during 2006-2016. Using partial correlation (PC) and ordinary correlation (OR) analyses, this research examines the relationship between ecological footprint (EF) and subjective well-being (SWB) to measure environmental impacts on people's happiness. Gross domestic product (GDP), urbanization rate (UR), literacy rate (LR), youth life expectancy (YLE), wage and salaried workers (WSW), political stability (PS), voice accountability (VA) are regarded as control variables. Total bio-capacity (TBC), ecological crop-land footprints (ECL), ecological grazing-land footprint (EGL), and ecological built-up land footprint (EBL) have significant positive influences on SWB, but ecological fish-land (EFL) has significant negative influences on SWB. Ecological carbon footprint (ECF) is significantly negatively related to SWB in developed countries. An increase in the amount of EF factors is associated with a country's degree of development. Political social-economic impacts on SWB disguised environmental contribution on SWB, especially CBF impacts on SWB. The use of PC in examining the association between SWB and EF helps bridge a knowledge gap and facilitate a better understanding of happiness.
\end{abstract}

Keywords: partial correlation; subjective well-being; ecological footprint; sustainability

\section{Introduction}

Gross National Happiness (GNH) was proposed by the 4th King, Jigme Singye Wangchuck of the Kingdom of Bhutan, as a new metric to measure human spiritual and material development, overwhelmingly capturing global attention [1]. Subjective Wellbeing (SWB), as an alternative of GNH in Western countries, aims at measuring happiness, suffering, and other dimensions of experience [2]. SWB is considered to be related to income, jobs, housing conditions, health, work and life balance, education, personal security, and social connections [3]. SWB comes from people's inner world, is an emotional reaction in response to objective materials. It is an important issue of explaining cross-country differences, and it may have an impact on the political culture of every single country [4].

Since SWB is a multiple-scale interdisciplinary notion of investigation, involving psychology, economics, sociology, and other disciplines, it is hard to identify SWB appropriately [5]. Concerning the socially important events such as marriage or divorce, SWB is easily obtained by opportunity costs within the short-term, instead, the environmental impacts on SWB are intangible, ignored, and complicated in the long-term period. Current SWB research focuses on the nonmaterial quality component of people's life [6,7] and the relationship between SWB and GDP. These research efforts draw primarily on the economic and psychology research field, rather than an environmental perspective [8]. Interestingly, the book of 'Culture and Subjective Well-being' gave us a fundamental and potential research paradigm [9], but it roughly modeled relationships between happiness and culture, not for environmental study. Only one publication in the Web of Science databases is relevant 
to investigation of environmental contribution of SWB. The study used a questionnaire implemented in Flanders (Belgium) to reveal the association between individual's ecological footprint to their SWB [10]. This study did not use data from different time periods in its analysis. Therefore, the result from this study has its limitations because it is of critical importance to take into consideration of the spatial-temporal linkage between EF and SWB in analysis of this nature [11].

Ecological footprint (EF) is a vital indicator for measuring environmental sustainability [12]. In 1996, an ecological footprint method was put forward by Wackernagel and Rees [13], via a rigorous resource accounting about how serious future resources were used to run the present using more than the Earth's replenishment. EF measures how much land humans need to produce all the resources they consume and to absorb the waste, using current technology and resource management systems $[14,15]$. The majority of EF studies have been carried out to unravel what affects the environment [16]. These studies generally examined the environmental consequences derived from human ecology, modernization, and political economy [17]. However, they did not mention how to compute ecological degradation, as the product of social, political, and economic relations.

Jorgenson [18] argued that growth of energy consumption was positively related to growth in urban population, negatively associated with increase in the percentage of a population living in urban slum conditions. Fang [19] proposed a 3D model with the EF depth and the EF size. Elliott and Clement [20] conducted cross-sectional and panel regression analyses of carbon emissions in United States using nationwide data, curbing for spatial autocorrelation. They showed urbanization countervail the local level to affect carbon emissions. Charfeddine and others [21] explained economic development and social-political factors on ecological footprint using a panel data analysis for 15 MENA countries. Zhao and colleagues [22] explored spatial-temporal footprint factors and created a united criterion for grading the evaluated consequences on global benchmarks to describe the environment of sustainable development deteriorated. Liu and other researchers [23] identified the relationship between environmental regulations and haze pollutions using dynamic and spatial econometric methods including global and local spatial autocorrelation. Additionally, they used seven socioeconomic drivers to check the impacts of spatial spillover on haze pollution, involving economic growth, industrial structure, foreign direct investment, population density, urbanization, transportation, and R\&D intensity.

Zhaohua [24] pointed out that freshwater did not contain the traditional ecological footprint accounting based on a modified ecological footprint model. Decun Wu used geographical weighted regression to explore the spatial-temporal relationship difference between EF and influencing factors in China's province [25]. Ecological degradation caused natural disasters leading to SWB reduction [26]. Although existing EF studies, ranging from static to 3D dynamic change, from urban population growth to panel regression analyses of carbon emissions, and from time series to spatial autocorrelation, have been well documented, environmental change from political economy, as a confluence between ecologically rooted social science and the principles of political economy, is so far blurred [27].

Material demands of production and human consumption challenge the capacity of the ecosystem $[28,29]$. The butterfly effect of human-environment linkages has caught many scholars' attention. These scholars explored the association between economic, political, and environmental factors from diverse perspectives [30-34]. Due to the loss of arable land, habitat destruction, the decline in natural vegetation cover, and global warming, ecological damage rooted in not just political economy, but also urbanization and geographic influences [35].

First, political, social, and economic factors have the roles in environmental deterioration. The world has undergone rapid economic growth due to its abundance of natural resources consumption and the transition of various economies from agriculture-based economies to industrial and service-based economies [36]. In particular, in less developed countries, rapid economic growth sometimes leads to environmental degradation, food 
insecurity, and impairment of human well-being [37-39]. For example, haze pollution in China is becoming increasingly serious [40,41]. In 2016, about 254 out of 338 cities could not meet the National Ambient Air Quality Standards of China, accounting for $75.1 \%$ of the environmental pollutions [23]. Thus, there is an extensive consensus among policymakers concerning an urgent and optimal economic policy that can help preserve and protect the environment of the region.

The issue-how to reach higher economic growth and urbanization without compromising the quality of the environment-has not been well addressed in some parts of the world [42]. There is also no consensus regarding environmental assessment criteria and ecological environmental evaluation system to examine the impact of the economy on the environment [43]. According to the Environmental Kuznets Curve (EKC) hypothesis, environmental degradation has risen from the beginning of economic growth to a turning point. After that, economic development benefits environmental improvements, which is called an inverted U-shaped link [44]. Previous studies on the association between economic growth and pollution concentrated on carbon dioxide released as a measuring standard of environmental reduction [45]. It is evident that carbon dioxide emission is a part of environmental degradation. EF is a synthetical indicator to examine the degree of environmental deterioration since it involves not just carbon footprint, but also many aspects such as different land consumptions. Therefore, many critical environmental scholars argue that environmental degradation is the result of the current structure of the political economy, globally and at more localized scales [46-50]. Some other scholars are in favor of de-growth as the best strategy forward in some parts of the world [51-53], but that aside, it is necessary to acknowledge at least the voluminous critiques of capitalist globalization's role in environmental degradation.

We agree that geographic factors in space and time are important elements when studying the relationship between EF and SWB. Therefore, exploring the spatial-temporal association between EF and SWB will help understand the relationship better and hence promote human well-being in a sustainable development process [54]. This paper aims to examine whether an endogenous relationship exists between EF and SWB and how many environmental factors influence SWB under different political, social, and economic conditions. It will further facilitate the understanding of SWB and offer insights regarding the relationships between humans and nature.

\section{Materials and Methods}

\subsection{Data}

Data used in the SWB assessment in the world were acquired directly from a variety of sources (e.g., Global Footprint Network, World Value Survey, Gallup World Poll) and in multiple formats. Representation of SWB changes with EF influential factors was employed by a panel data from 2006-2016, including cross-section and longitudinal two sections.

SWB refers to how people experience the quality of their lives and it includes both emotional reactions and cognitive judgments [55]. It stems from the world SWB report 2019 data, from which is the Gallup World Poll. It is a large-scale repeated cross-sectional survey involving more than 150 countries. The period covered in our research is from 2006 to 2016. All samples in the poll are probability based and nationally representative of the resident population aged 15 and older. The typical Gallup World Poll survey wave interviewed 1000 individuals using answers to a Cantril Ladder question. Life satisfaction was measured on a 10-point scale. EF is one of the ways to measure humans' consumptions, using current technology and resource management systems. The EF is usually expressed in global hectares. In general, EF means the ecological footprint of consumption. EF data consists of cropland footprints, grazing-land footprints, forestland footprints, fishing-land footprints, built-up footprints, and carbon footprints. All the data were obtained from the global footprint network [56]. The data collected in this study covered 101 countries from 2006 to 2016, as shown in Table 1. 
Table 1. Variables used for exploring the association between Subjective Well-Being (SWB) and Ecological Footprint (EF).

\begin{tabular}{|c|c|c|c|}
\hline Category & Variable Name & Acronym & Variable Description \\
\hline Dependent variable & Subjective well-being & SWB & Happiness degree of a country \\
\hline \multirow{8}{*}{$\begin{array}{l}\text { Independent } \\
\text { variables }\end{array}$} & Bio-capacity & $\mathrm{BC}$ & The ecosystems' capacity \\
\hline & Carbon footprint & $\mathrm{CBF}$ & $\begin{array}{l}\text { The size of forest land needed to contain anthropogenic } \\
\text { carbon dioxide emissions }\end{array}$ \\
\hline & Cropland footprint & CLF & $\begin{array}{l}\text { The footprint of cropland incorporated in crop products and } \\
\text { feed products for livestock and fish. }\end{array}$ \\
\hline & Fishing land footprint & FIF & $\begin{array}{l}\text { The footprint of marine and inland water area embodied in } \\
\text { fish and other aquatic products. }\end{array}$ \\
\hline & Built-up land footprint & BLF & The footprint related to infrastructure \\
\hline & Forestland footprint & FLF & $\begin{array}{l}\text { The forest products footprint embodied in primary and } \\
\text { secondary forest products }\end{array}$ \\
\hline & Grazing-land footprint & GLF & $\begin{array}{l}\text { The footprint of pasture grass embodied in } \\
\text { livestock products }\end{array}$ \\
\hline & $\begin{array}{l}\text { EF consumption } \\
\text { per capital }\end{array}$ & EF & $\begin{array}{l}\text { How much land humans need to produce all the resources } \\
\text { they consume and to absorb the waste }\end{array}$ \\
\hline \multirow{3}{*}{$\begin{array}{l}\text { Control variables } \\
\text { Economic }\end{array}$} & GDP per capital & & $\begin{array}{l}\text { Measuring economic performance by amassing the value of } \\
\text { all the goods and services produced within a country }\end{array}$ \\
\hline & Urbanization rates & URB & The growth of population urbanization \\
\hline & $\begin{array}{l}\text { Wage and salaried } \\
\text { workers }\end{array}$ & WSW & $\begin{array}{l}\text { The number of those workers who had jobs defined as } \\
\text { "paid employment jobs" }\end{array}$ \\
\hline Education & Literacy rate & LR & $\begin{array}{l}\text { The percentage of people aged } 15-24 \text { who can both read and } \\
\text { write with understanding a short simple statement about } \\
\text { their everyday life }\end{array}$ \\
\hline Health & Youth life expectancy & YLE & The number of years a newborn is expected to live \\
\hline \multirow{2}{*}{ Political } & Political stability & PS & $\begin{array}{l}\text { The possibility of political instability and/or politically } \\
\text { motivated violence }\end{array}$ \\
\hline & Voice accountability & VA & $\begin{array}{l}\text { Those which a country's citizens can take part in selecting } \\
\text { their government, freedom of ideas, freedom of association, } \\
\text { and an open media }\end{array}$ \\
\hline
\end{tabular}

In this paper, SWB is a dependent variable. GDP per capita, urbanization rates, literacy rate, youth life expectancy, wage and salaried workers, political stability, and voice accountability are control variables. Bio-capacity, carbon footprint, cropland footprint, fishing land footprint, built-up land footprint, forestland footprint, grazing-land footprint, and EF consumption per capital are independent variables. Control variables were extracted from the World Bank and the World Value Survey (http:/ / www. worldvaluessurvey.org/wvs.jsp). Survey SWB were extracted from the Gallup World Poll (https://www.gallup.com/analytics/318875/global-research.aspx), as shown in Figure 1. Figure 1 illustrates the hidden connections between SWB and EF and how they are related to the control variables. 


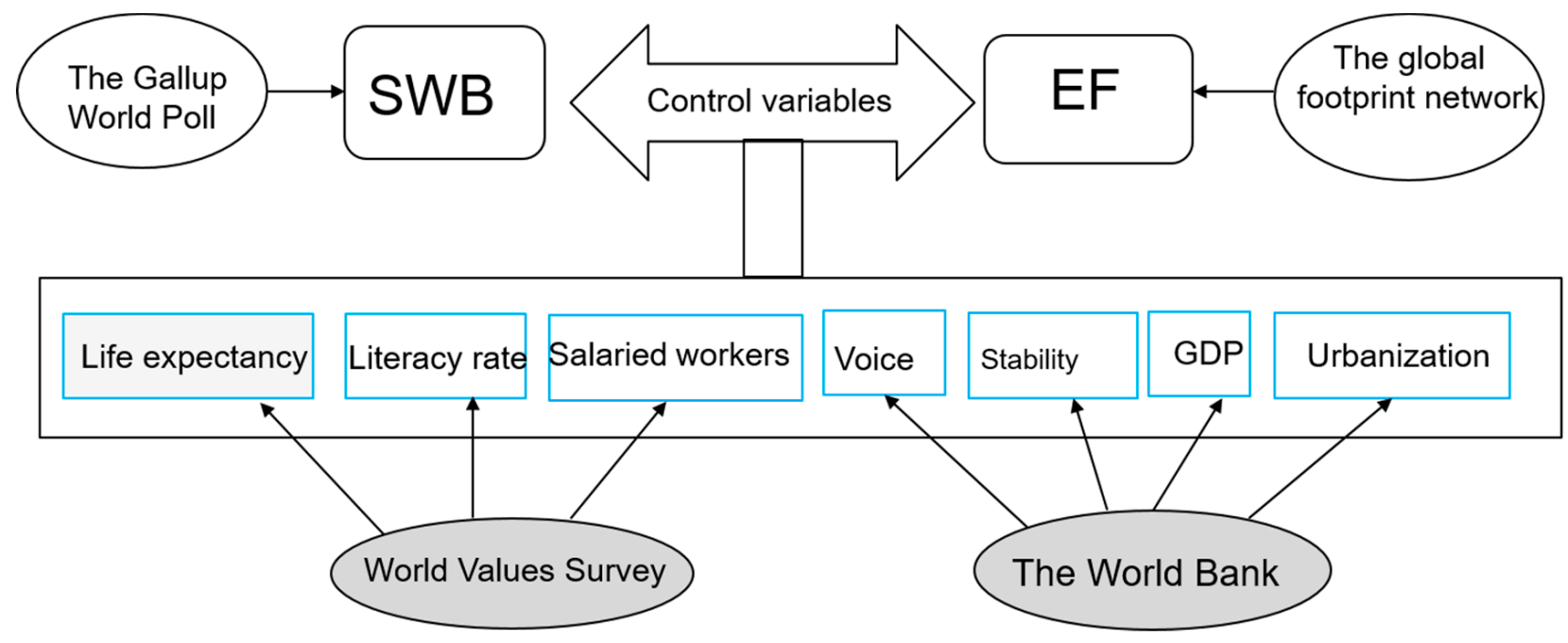

Figure 1. Data source framework.

\subsection{Study Area}

This study covers 101 countries in the world, excluding countries/regions with missing data (Figure 2). Countries are classified as undeveloped, developing, developed, and advanced countries based on GDP per capita.

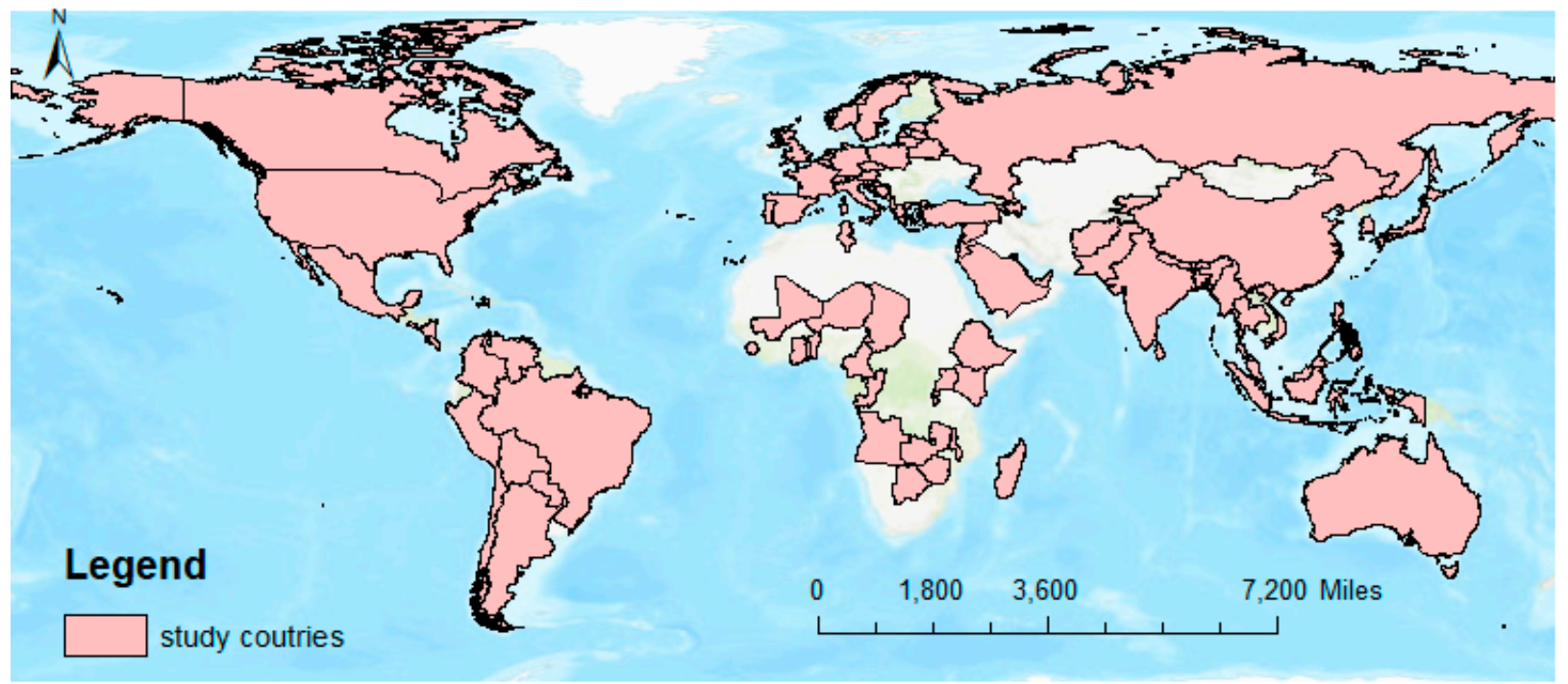

Figure 2. Investigated countries distribution map.

\subsection{Study Framework}

In this paper, through modeling PC, three layers were obtained to examine the association between SWB and EF. The first layer is to compare different methods, called external contrasts, which pay attention to variable coefficients change between PC and OC methods; the second layer is to compare different levels of countries, called spatial disparity, meaning all countries are divided into four categories, undeveloped, developing, developed, and advanced countries. The last layer is the time series difference between EF factors in a spatial fixed condition, called longitudinal distinctions. The study framework is shown in Figure 3. 


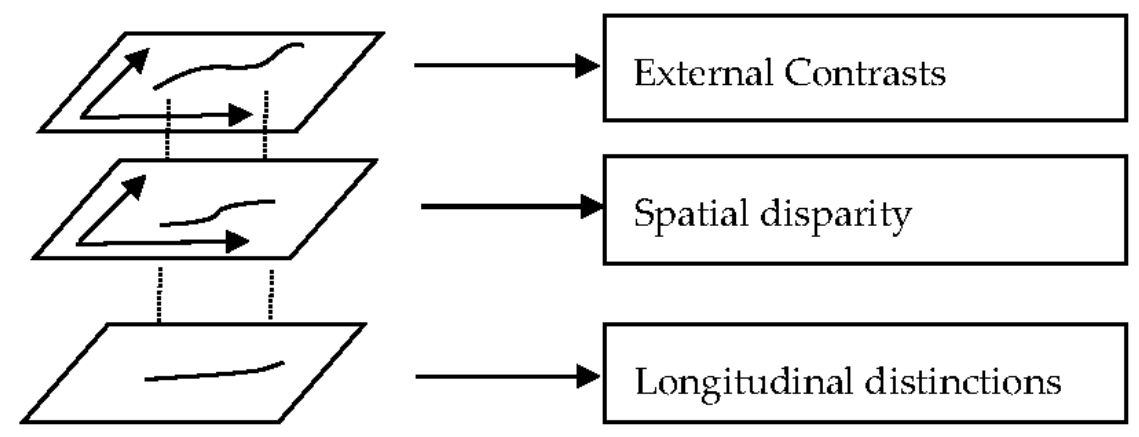

Figure 3. Study framework.

\subsection{Normalization}

Normalization is the process of making sure that the dataset can be compared to other data sets. It is a key part of the research because normalized data is essential for accurate data analysis. It is easier to draw clear conclusions about current data when there are other data to measure it against. To identify the comparison of different indexes, the following formula was used to normalize the individual index ranging from 0 to 1 in value.

$$
k_{i}= \begin{cases}100 \times\left(a_{i}-a_{\min }\right) /\left(a_{\max }-a_{\min }\right), & \text { if } k_{i}>0 \\ 100 \times\left(a_{\max }-a_{i}\right) /\left(a_{\max }-a_{\min }\right), & \text { if } k_{i} \leq 0\end{cases}
$$

where $k_{i}$ denotes the weight of standardized value; $a_{i}$ denotes the original value of the individual index; $a_{\max }$ is the maximum value of the individual index, $a_{\min }$ is the minimum value of the individual index.

\subsection{Modeling PC}

Partial correlation is used to measure the linear relationship between two continuous variables while controlling for the effect of one or more other continuous variables. Based on findings from previous studies, SWB is considered to be related to seven traditional factors including GDP, URB, LR, YLE, PS, VA, and WSW. These seven traditional factors were used as control variables in this study to conduct a partial correlation analysis to reveal the association between SWB and EF. In addition, this study examined the difference between the results from ordinary correlation and partial correlation analyses.

The following process is needed to construct the PC model. First, a covariance matrix $(\Sigma)$ is estimated. Second, the correlation matrix $(C)$ through a normalization of the offdiagonal entries is determined.

$$
C_{i j}=\frac{\sum i j}{\sqrt{\sum i i \sum j j}}
$$

The partial correlation matrix can also be obtained in the same way. Third, the diagonal entries of the inverse of the covariance matrix $(\Theta)$ are peeled off and the partial correlation matrix $(P)$ is computed using Equation (2):

$$
P_{i j}=-\frac{\Theta_{i j}}{\sqrt{\Theta_{i i} \Theta_{j j}}}
$$

Finally, based on Equation (3), $\beta_{i j}^{*}$ as the weight of the partial correlation between $i$ and $j\left(P_{i j}\right)$, is obtained [57]:

$$
\beta_{i j}^{*}=-\frac{\Theta_{i j}}{\Theta}=P_{i j} \sqrt{\frac{\Theta_{j j}}{\Theta_{i i}}}
$$




\section{Results}

\subsection{External Contrasts}

To make a comprehensive comparison between the two methods, both the correlation coefficients obtained through the OC analysis and partial correlation coefficients obtained through the PC analysis are listed in Table 2 along with their significance descriptions. Table 2 shows us the result of a comparison of OC and PC.

Table 2. Comparison of ordinary correlation (OC) and partial correlation (PC) analyses.

\begin{tabular}{ccc}
\hline \multirow{2}{*}{ Factors } & Ordinary Correlation & Partial Correlation \\
\cline { 2 - 3 } & Coef./Prob. & Coef./Prob. \\
\hline EF & $0.70 / 0.00$ & $0.003 / 0.900$ \\
\hline BC & $0.30 / 0.00$ & $0.150 / 0.000$ \\
\hline CBF & $0.65 / 0.00$ & $-0.040 / 0.140$ \\
\hline CLF & $0.55 / 0.00$ & $0.070 / 0.040$ \\
\hline FIF & $0.35 / 0.00$ & $-0.080 / 0.020$ \\
\hline FLF & $0.31 / 0.00$ & $0.016 / 0.600$ \\
\hline GLF & $0.26 / 0.00$ & $0.160 / 0.000$ \\
\hline BLF & $0.42 / 0.00$ & $0.110 / 0.001$ \\
\hline
\end{tabular}

Note: Coefficients in bold indicate the correlation is not statistically significant.

The output of the ordinary correlation analysis among SWB and its EF related factors involve BC, EF, ELF, GLF, FLF, FIF, BLF, and CBF in Table 2. First, in all 101 countries, their probabilities are equal to 0 , less than 0.05 , and all coefficients are more than 0 . These results suggest that EF influential factors are positively related to $\mathrm{SWB}$, indicating $\mathrm{EF}$ factors are proportional to SWB without considering political social-economic impacts. Second, based on the ordinary correlation analysis results, EF has a coefficient value of 0.7 which is the largest among influential factors. GLF has a coefficient value of 0.26 that is the smallest. The results mean that EF's influence on SWB is the highest and GLF is the lowest. In other words, human consumptions are directly related to human happiness. In addition, with a coefficient value of $0.65, \mathrm{CBF}$ is positively related to $\mathrm{SWB}$, meaning carbon emission has an effect on people's feelings of happiness. It can be interpreted as more carbon emissions generate more waste, leading to enhance individual life satisfaction. This result is consistent with findings in previous studies about why humans indulge in all sorts of everyday bodily or mental pleasure via hedonic motivation on buying nexus as well [58,59].

When considering the impacts of control variables as shown in the results of the PC analysis in Table 2, SWB is positively related to BC, BLF, CLF, GLF and negatively related to FIF. That describes that the more natural resources or space that one occupies, the more delight one feels. An increase in built-up land is due to city expansion, an increase of cropland and grazing land reflects fish-land reductions. It implies two meanings. One is the number of grazing-lands directly affects the capacity of natural supply. The other is the human consumption of a variety of land determined bio-capacity change. EF is positively significantly related to FLF, CLF, and CBF, especially the coefficient between EF and CBF reached 0.91. It is emphasized that carbon emission is the main influential factor of $\mathrm{EF}$ varying. However, BLF is positively related to CLF and FLF, negatively related to CBF and FIF, indicating agricultural development and forest protection reduce carbon emission and inhibit urban expansion. CBF is similar to BLF, positively related to CLF and FLF, but negatively related to GLF and FIF. It implies that carbon consumption is a ramification of city sprawl, result in increase of built-up land. CLF is positively significantly related to FLF, FIF is negatively significantly related to GLF and FLF. It means land cover arises from filling water area. 
When control variables are considered, three remarkable distinctions are generated in terms of comparing two correlations. Firstly, the value of correlation is less likely than that without any controlling, for example, BC, GLF, BLF, and CLF coefficients declined from $0.3,0.26,0.42,0.55$ to $0.15,0.16,0.11,0.07$, respectively, presenting control variables hid environmental impacts on SWB. i.e., as long as political, social-economic factors are considered, the coefficients of environmental factors are less than 0.2 , so they are ignored. Secondly, the CBF and FIF have negative effects on SWB. Meanwhile the BC, EF, CLF, FLF, GLF, and BLF have positive effects on SWB in Table 2. Carbon emission increases and filling water areas is likely to cause happiness reductions. Notwithstanding, the CBF probability of 0.14 is more than $p$-value 0.05 , delineating that there is no significant impacts. The FIF probability of 0.02 is less than 0.05 , meaning FIF is significant to SWB. The possibility might be thought that the action of filling water produces more space for people's utilization whereas more marital and space possession facilitates happiness enhancing. Finally, the probabilities of EF and FLF are 0.9 and 0.6, respectively, beyond 0.05, indicating they are insignificant to SWB. Accordingly, although political social-economic impacts on SWB are tangible and remarkable, they impeded or misunderstood environmental contribution on SWB, especially disguised CBF impacts on SWB.

\subsection{Spatial Disparity}

To show further different effects, the partial correlation analysis was conducted for the development of the different-level countries, respectively. The results are shown in Table 3.

Table 3. Different level correlation list.

\begin{tabular}{ccccc}
\hline Correlation & SWB & SWB & SWB & SWB \\
\hline Probability & Undeveloped & Developing & Developed & Advanced \\
\hline BC & 0.19 & 0.04 & 0.15 & 0.24 \\
& 0.01 & 0.55 & 0.02 & 0.00 \\
EF & 0.01 & -0.03 & -0.00 & -0.11 \\
& 0.86 & 0.68 & 0.97 & 0.05 \\
BLF & 0.28 & -0.10 & 0.02 & 0.18 \\
& 0.00 & 0.17 & 0.70 & 0.00 \\
CBF & 0.07 & 0.16 & -0.15 & -0.14 \\
& 0.34 & 0.02 & 0.02 & 0.01 \\
CLF & -0.01 & -0.27 & -0.02 & 0.23 \\
& 0.88 & 0.00 & 0.79 & 0.00 \\
FIF & 0.13 & -0.15 & 0.004 & -0.11 \\
& 0.10 & 0.03 & 0.95 & 0.05 \\
FLF & 0.06 & -0.07 & 0.16 & -0.08 \\
& 0.42 & 0.35 & 0.01 & 0.14 \\
GLF & -0.08 & 0.06 & 0.21 & 0.23 \\
& 0.33 & 0.39 & 0.00 & 0.00 \\
\hline
\end{tabular}

In the undeveloped countries, average EF and BC are 1.12 and 1.39, respectively, by 170 records. BC and BLF have positive effects on SWB. Two factors of EF contribute to SWB. It reflects that economically undeveloped countries paid more attention to natural resource utilization, instead of high technology updating. In the developing countries, based on 203 records, EF and BC mean are 1.58 and 1.95 within the study period. CBF has positive effects on SWB while FIF and CLF are significantly negatively related to SWB. There are three available factors in the relationship. It means rapid economic development in developing countries brought about an increase in carbon emission. At the same time, water and cropland areas have been shrunk by the extraction of construction land. In the developed countries, EF and BC mean are 3.13 and 3.11 during 2006-2016 in light of 254 qualified records.

Four EF factors contribute to SWB. BC, FLF, and GLF have positive effects on SWB and CBF negatively affect SWB. That points out that there are environmental improvements in 
developed countries due to carbon footprint reduction. Besides, the growth of resource demand leads to SWB escalation. In the advanced countries, EF and BC mean are 6.07 and 3.21 during 2006-2016 via 338 observations. EF and CBF have negative effects on SWB. Meanwhile, BC, BLF, CLF, and GLF have positive effects on SWB. There are five indexes of EF affecting SWB. The fact that can be obtained is that high technology and eco-friendly energy application lead to carbon emission and EF shrinking with SWB upsurge. Simultaneously, energy competition is taken as a normal phenomenon for granted. Indeed, it is a matter of the notion of pseudo-environment. Energy combating is to develop useful and clean energy, rather than traditional energy abuse.

Compared to the four levels of EF and $\mathrm{BC}$ mean, the fact that should be noticed is that $\mathrm{EF}$ and $\mathrm{BC}$ increase with the development degree. It is also highlighted that the factors of $\mathrm{EF}$ generated a higher possibility of SWB impacts under different developing levels increased from 2 to 5 . Thus, it can be concluded that the acknowledgment of the environment and happiness are strengthened.

\subsection{Longitudinal Distinctions}

Table 4 provides four valuable outcomes through time-series comparisons. First, the period from 2006 to 2016 is bestowed a decreased trend in average EF and BC in advanced countries. In light of Table 4, the EF mean is decreased from 6.28 to 5.93 while BC is declined the range 2.66-2.5 in advanced countries within a decade, indicating good environmental consciousness is formed and high technology are implemented, instead of depending on traditional energy. Second, average $\mathrm{BC}$ was presented adversely in undeveloped countries. $\mathrm{BC}$ mean is raised from 1.32 to 1.42 , exhibiting that economic development lagged behind and left everything to fate in the region. That also explained that undeveloped countries extremely rest on environmental behaviors "stem primarily from a concern with livelihood" and are engaged with "productive use of natural resources" [60,61], lacking high technology and new energy support. Third, BC mean in undeveloped countries is just a half of BC mean in advanced countries. It means extraordinary waste in advanced countries existed. For instance, the United States has the third-largest population of all countries, and it produced the most municipal solid waste (MSW) in the world: 258 million tons of MSW was generated in 2017. The most populous country in the world, China, on the other hand, generated 210 million tons of MSW in 2017. At last, Table 4 tells us the fact that BC is sensitively related to SWB change over time, compared to EF. BC mean change speeds in $6.02 \%$ of advanced countries and $7.58 \%$ of undeveloped countries are higher than EF mean change speed of $5.57 \%$. It described that ecological capacity is flexible and has a characteristic of nonstationary. It is understood that anthropogenic activities deiminated production capability so that $\mathrm{BC}$ represented disparity of nature functions in the different countries in the world.

Table 4. Time-series distinctions list.

\begin{tabular}{cccc}
\hline Index & Country Type & 2006-2010 & 2011-2016 \\
\hline EF Mean & Advanced countries & 6.28 & 5.93 \\
BC Mean & Advanced countries & 2.66 & 2.50 \\
BC Mean & Undeveloped countries & 1.32 & 1.42 \\
\hline
\end{tabular}

\subsection{CBF and BC Impacts on SWB}

Through the three above aspects analysis, carbon emission is negatively significantly related to SWB in developed countries and advanced countries, looking at Table 3. Table 3 shows the PC analysis for EF related factors impact on SWB with control variables in the developed level. CBF's coefficient is $-0.14, p$-value is 0.01 , less than 0.05 . Negative impacts on SWB account for what means happiness in developed countries. When people realize the importance of environmental protection and consider recycling as daily necessary, environmental benefits bring good feelings. For example, in the US, green lands around houses should be maintained by homeowners. People spontaneously keep cleaning and 
irrigating in regular time. Table 3 also displays the PC analysis for EF related factors impact on SWB with control variables in advanced level. CBFs coefficient is $-0.14, p$-value is 0.01 , less than 0.05 . The negative effect of CBF is significant relevant to SWB, which matches the current situation of developed countries. As matter of fact, $\mathrm{CBF}$ is the main part of EF, taking up over $70 \%$ of EF. Carbon emission is close to environmental quality degradation. Thus, reducing carbon emission is a good way to increase SWB. Low-carbon daily life also might be an underlying, sustainable development trend in the future. It is believed that within the continuous improvement of the human development index and the popularity of the concept of ecological protection, the low-carbon circular economy model will be an underlying, sustainable development trend to mitigate environmental pressure and improve happiness satisfaction from being enforced by the government to people's subjective consciousness.

In the context of partial regression analysis, it is, no doubt, that SWB is more likely related to $\mathrm{BC}$ wherever the development level is, compared to EF. In fact, $\mathrm{BC}$ is the consequence of the area available for a given land use type multiplying the yield factor and equivalence factor. The yield factor is the ratio of the national average to world average yields. The equivalence factor is to weight different land areas in terms of their capacity to produce resources useful for humans, based on the Global Agro-Ecological Zones model (GAEZ). The GAEZ model divides all land globally into five types, such as very suitable, suitable, moderately suitable, marginally suitable, and not suitable (FAO and IIASA Global Agro-Ecological Zones 2000 FAO Resources STAT Statistical Database 2007). Since the area value of one country is fixed, two factors are estimated to constants. TBC literally is inflexible in individual countries in a period. Compared to BC, EF is calculated by human consumption in different years, which involves the impact of trade import and export, as well as population growth.

Furthermore, BC accounts for positive 0.15 coefficient, just lower than GLF coefficient, higher than other EF factors, adding $p$-value of $B C$ less than 0.05 , significantly positive influences on SWB. That reflects two sides of an interaction process. SWB is human perspectives for nature or surrounds their milieu. $B C$ is a nature offering based on its capacity. An increase of SWB will bring an increase of $\mathrm{BC}$, which might be restricted by advanced technology and environmental conservation depth. On the other hand, regarding the concept of $\mathrm{EF}, \mathrm{BC}$ increasing leads to ecological deficit reduction in the context of fixed EF. Those further indicate that the pursuit of SWB growth is not in conflict with EF shrinking. The reason is that EF shrinking is ecological deficit reduction or ecological reserve increase, not $\mathrm{EF}$ reduction. In other words, EF increasing is normal, but it might lower the speed of $\mathrm{BC}$ increasing result from $\mathrm{EF}$ expansion rests on $\mathrm{BC}$ coordination. Thus, a shrinking ecological deficit or environmental improvement benefits humans in desires of happiness. With sufficient sampling size and strong statistical significance $(p<0.001)$, the results of regression analysis have a clear correlation between EF and SWB long term.

\section{Discussion}

\subsection{Significance of Research}

This study tried to expose the spatial-temporal different correlation between EF and SWB. In the aspect of spatial distributions of EF, four categories of countries' development levels were used to explain EF factors impacts on SWB. There are different variables and numbers of factors that impact SWB at different levels based on their development demands. It is coincident with peoples' acknowledgement of environmental SWB that is becoming more intensified. To some content, it is reflected that people's demand for the environment is gradually restricted so that SWB incorporates more significance. With the advent of high technology and data age, environmental pressure and the need for natural resources are mitigated, carbon emission and BC are reduced in developed and advanced countries but still increased in developing and undeveloped countries. Spatial variabilities are provided through experimental explanations of 101 countries' investigated data in the research. In the aspect of longitudinal disparity, $\mathrm{BC}$ consumption increased in undeveloped 
countries and declined in advanced countries. That aligned with spatial heterogeneity, SWB understanding is different from spatial-temporal varying.

Under the context of PC with consideration of control variables, environmental impacts on SWB are less than control variables. However, environmental influences have never stopped work on SWB. With the time change, BC contributed to SWB more than EF. BC is changed by SWB demands. It exhibits EF factors' roles in SWB. No matter how small, people's satisfaction with happiness includes environmental justice. Hence, this research gives us scientific evidence about the environmental impact on SWB. At the same time, this research proposed that $\mathrm{CBF}$ accounts for over $90 \%$ of $\mathrm{EF}$ so that reducing carbon emission is crucial for EF shrinking. It also indirectly affects happiness index enhancement.

Existing SWB measurement is a survey by qualitative research. This research offered an underlying quantitative method to measure SWB via the synthetical index of using social-economic and environmental variables. It not only makes up missing data of SWB in the past but also saves time and cost of questionnaires.

Currently, China has undergone rapid urbanization and economic development, but was accompanied by severe environmental issues and the related public health burdens. China's Cabinet, the State Council, advocated a work plan for the zero-waste city pilot project. The pilot plan aims for the minimum generation, maximum utilization, and safe disposal of solid waste. The use of landfills will be minimized as part of efforts to reduce the environmental impact of waste. A zero-waste city refers to an advanced urban development and management model that tries to promote green lifestyles, minimize the amount of waste produced, strengthen recycling programs, and ensure that waste released into the environment is harmless. Construction of the pilot zero-waste city project is of great significance to promote and deepen comprehensive reform of urban solid waste management, and it is an important measure to realize the ecological civilization and build a beautiful China. It intends to be a replicable program that realizes the nation's zero-waste target. Our research could help examine its implementation and provide a new direction for future sustainable development of environments in China.

\subsection{Limitations and Future Research}

To begin with, EF on the global network does not include water footprints. With the scarcity of freshwater, water requirement and consumption are a part of EF. Attention is supposed to be paid to add it to the global footprints network. What is more, the identification of both equivalence factors and yield factors needs more consideration of geographic disparity. This is not only because the different geologic structure has impacts on EF change, but it also because aggregation of population and industrialization caused environmental change. Besides, government policies contribute to SWB on environmental influence. When a new leader of a country comes out, there are so many policies that would be changed, inevitably leading to SWB decline. All these not noticed in this work should be taken more seriously later on.

\section{Conclusions}

The harmonious development between SWB and the environment system is a dynamic, rather than a static, process. Multiple dimensional disparity of environmental SWB is an important issue that deserve more attention from researchers. The existing literature has discussed this intensively from psychological perspectives. Social-economic considerations have been found in limited explanatory power for multiple dimensional disparity of environment in the study of SWB and environmental factors. This study takes advantage of the partial correlation (PC) analysis method to investigate the partial correlation between SWB and EF with controlled social and economic conditions. It shows that environment is regarded as a possible factor that affects SWB disparity in methodology and spatialtemporal changes. Therefore, the results of this study provide empirical evidence to support future environmental research about happiness. 
At present, few methods exist to study the relationship between EF and SWB. The PC analysis used in this study could accurately estimate the spatial-temporal variabilities of association between EF and SWB. Thus, this method is applicable in other similar situations where there is an issue about selecting significantly correlated variables at various geographical locations during different time periods. Our results confirmed the findings of existing work on EF but extend it to environmental health by PC analysis of the association between SWB and EF related factors in the world.

Author Contributions: Conceptualization and methodology, X.W. and J.Z.; investigation, resources, and data curation, X.W.; writing - original draft preparation, X.W.; writing, reviewing, and editing, J.Z., F.B.Z. and D.Z.; supervision and project administration, F.B.Z.: reviewing, writing, and editing. All authors have read and agreed to the published version of the manuscript.

Funding: This research received no external funding.

Institutional Review Board Statement: Not applicable.

Informed Consent Statement: Not applicable.

Data Availability Statement: All data, models, and code generated or used during the study appear in the submitted article.

Conflicts of Interest: The authors declare no conflict of interest.

\section{References}

1. Schroeder, R.; Schroeder, K. Happy Environments: Bhutan, Interdependence and the West. Sustainability 2014, 6, $3521-3533$. [CrossRef]

2. Well-Being: The Foundations of Hedonic Psychology. Available online: https://search-ebscohost-com.libproxy.txstate.edu/login. aspx?direct=true\&db=cat00022a\&AN=txi.b3794153\&site=eds-live\&scope=site (accessed on 20 January 2021).

3. Subjective Well-Being: Measuring Happiness, Suffering, and Other Dimensions of Experience. Available online: https://searchebscohost-com.libproxy.txstate.edu/login.aspx?direct=true\&db=psyh\&AN=2013-45648-000\&site=eds-live\&scope=site $($ accessed on 20 January 2021).

4. Ye, S.; $\mathrm{Ng}, \mathrm{T} . \mathrm{K}$. Value change in response to cultural priming: The role of cultural identity and the impact on subjective well-being. Int. J. Intercult. Relat. 2019, 70, 89-103. [CrossRef]

5. Evans, G.F.; Soliman, E.Z. Happier countries, longer lives: An ecological study on the relationship between subjective sense of well-being and life expectancy. Glob. Health Promot. 2020, 26, 36-40. [CrossRef] [PubMed]

6. Llosada-Gistau, J.; Casas, F.; Montserrat, C. The subjective well-being of children in kinship care. Psicothema 2019, 31, 149-155. [PubMed]

7. You, S.; Lim, S.A. Religious Orientation and Subjective Well-being: The Mediating Role of Meaning in Life. J. Psychol. Theol. 2018, 47,34-47. [CrossRef]

8. De Neve, J.-E.; Ward, G.W.; De Keulenaer, F.; Van Landeghem, B.; Kavetsos, G.; Norton, M.I. The Asymmetric Experience of Positive and Negative Economic Growth: Global Evidence Using Subjective Well-Being Data. Rev. Econ. Stat. 2018, 100, 362-375. [CrossRef]

9. Culture and Subjective Well-Being. Available online: https://search-ebscohost-com.libproxy.txstate.edu/login.aspx?direct=true\& $\mathrm{db}=$ cat00022a\&AN=txi.b1494391\&site=eds-live\&scope=site (accessed on 20 January 2021).

10. Verhofstadt, E.; Van Ootegem, L.; Defloor, B.; Bleys, B. Linking individuals' ecological footprint to their subjective well-being. Ecol. Econ. 2016, 127, 80-89. [CrossRef]

11. Browning, M.H.E.M.; Lincoln, R.L.; Sharaievska, I.; Rigolon, A.; McAnirlin, O.; Mullenbach, L.; Cloutier, S.; Vu, M.T.; Thomsen, J.; Reigner, N.; et al. Psychological Impacts from COVID-19 among University Students: Risk Factors across Seven States in the United States. PLoS ONE 2021, 16. [CrossRef]

12. Ecological Footprint Assessment of Building Construction. Available online: https://search-ebscohost-com.libproxy.txstate.edu/ login.aspx?direct=true\&db=e000xna\&AN=1092446\&site=ehost-live\&scope=site (accessed on 20 January 2021).

13. Lin, D.; Hanscom, L.; Murthy, A.; Galli, A.; Evans, M.; Neill, E.; Mancini, M.S.; Martindill, J.; Medouar, F.-Z.; Huang, S.; et al. Ecological Footprint Accounting for Countries: Updates and Results of the National Footprint Accounts, 2012-2018. Resources 2018, 7, 58. [CrossRef]

14. Calculation Methodology for the National Footprint Accounts. Available online: https://www.footprintnetwork.org/content/ images/uploads/National_Footprint_Accounts_Method_Paper_2010.pdf (accessed on 19 January 2021).

15. Sukpasjaroen, K.; Chankoson, T. Measuring the Impact of Inbound Tourists, Outbound Tourists and Overall Tourism Growth on Sustainable Ecological Footprint of ASEAN Countries: A Panel Data Analysis. Contemp. Econ. 2020, 14, 487-497. [CrossRef] 
16. Bello, M.O.; Solarin, S.A.; Yen, Y.Y. The impact of electricity consumption on $\mathrm{CO}_{2}$ emission, carbon footprint, water footprint and ecological footprint: The role of hydropower in an emerging economy. J. Environ. Manag. 2018, 219, 218-230. [CrossRef] [PubMed]

17. Footprints on the Earth: The Environmental Consequences of Modernity. Available online: https://search-ebscohost-com. libproxy.txstate.edu/login.aspx?direct=true\&db=edsjsr\&AN=edsjsr.1519769\&site=eds-live\&scope=site (accessed on 20 January 2021).

18. Jorgenson, A.K.; Rice, J.; Clark, B. Cities, Slums, and Energy Consumption in Less Developed Countries, 1990 to 2005. Organ. Environ. 2010, 23, 189-204. [CrossRef]

19. Fang, K. Ecological Footprint Depth and Size: New Indicators for a 3D Model. Shengtai Xuebao/Acta Ecol. Sin. 2021, 33, 267-274. [CrossRef]

20. Elliott, J.R.; Clement, M.T. Developing spatial inequalities in carbon appropriation: A sociological analysis of changing local emissions across the United States. Soc. Sci. Res. 2015, 51, 119-131. [CrossRef] [PubMed]

21. Charfeddine, L.; Mrabet, Z. The impact of economic development and social-political factors on ecological footprint: A panel data analysis for 15 MENA countries. Renew. Sustain. Energy Rev. 2017, 76, 138-154. [CrossRef]

22. Zhao, X.; Ma, C.; Zhao, X.; Wang, X. Spatio-Temporal Dynamic Analysis of Sustainable Development in China Based on the Footprint Family. Int. J. Environ. Res. Public Health 2018, 15, 246. [CrossRef]

23. Liu, X.; Li, L.; Ge, J.; Tang, D.; Zhao, S. Spatial Spillover Effects of Environmental Regulations on China's Haze Pollution Based on Static and Dynamic Spatial Panel Data Models. Pol. J. Environ. Stud. 2019, 28, 2231-2241. [CrossRef]

24. Wang, Z.; Yang, L.; Yin, J.; Zhang, B. Assessment and prediction of environmental sustainability in China based on a modified ecological footprint model. Resour. Conserv. Recycl. 2018, 132, 301-313. [CrossRef]

25. $\mathrm{Wu}, \mathrm{D}$. Spatially and temporally varying relationships between ecological footprint and influencing factors in China's provinces Using Geographically Weighted Regression (GWR). J. Clean. Prod. 2020, 261, 121089. [CrossRef]

26. Liu, L.; Wang, H.-J.; Yue, Q. China's coastal wetlands: Ecological challenges, restoration, and management suggestions. Reg. Stud. Mar. Sci. 2020, 37, 101337. [CrossRef]

27. Liberation Ecologies: Environment, Development and Social Movements. Available online: https://search-ebscohost-com libproxy.txstate.edu/login.aspx?direct=true\&db=nlebk\&AN=116146\&site=eds-live\&scope=site (accessed on 20 January 2021).

28. Huang, S.-L.; Yeh, C.-T.; Chang, L.-F. The transition to an urbanizing world and the demand for natural resources. Curr. Opin. Environ. Sustain. 2010, 2, 136-143. [CrossRef]

29. Zhang, D.; Ge, W.; Zhang, Y. Evaluating the vegetation restoration sustainability of ecological projects: A case study of Wuqi County in China. J. Clean. Prod. 2020, 264, 121751. [CrossRef]

30. The Emerging Cultures of Capitalism: From the 'Clash of Civilizations' to 'Unity in Diversity. Available online: https://searchebscohost-com.libproxy.txstate.edu/login.aspx?direct=true\&db=edb\&AN=27581391\&site=eds-live\&scope=site (accessed on 20 January 2021).

31. Ye, M.; Aldrich, D.P. How natural hazards impact the social environment for vulnerable groups: An empirical investigation in Japan. Nat. Hazards 2021, 105, 67-81. [CrossRef]

32. Uzelac, O.; Davidovic, M.; Mijatovic, M.D. Legal framework, political environment and economic freedom in central and Eastern Europe: Do they matter for economic growth? Post-Communist Econ. 2020, 32, 697-725. [CrossRef]

33. Mohd, S.N.; Sharif, A.; Afshan, S.; Suki, N.M. Revisiting the Environmental Kuznets Curve in Malaysia: The Role of Globalization in Sustainable Environment. J. Clean. Prod. 2020, 264. [CrossRef]

34. Birch, S. Political polarization and environmental attitudes: A cross-national analysis. Environ. Politics 2019, 29, 697-718. [CrossRef]

35. Zhang, D.; Jia, Q.; Xu, X.; Yao, S.; Chen, H.; Hou, X.; Zhang, J.; Jin, G. Assessing the coordination of ecological and agricultural goals during ecological restoration efforts: A case study of Wuqi County, Northwest China. Land Use Policy. 2019, 82, 550-562. [CrossRef]

36. Lanouar, C.; Kahia, M. Impact of renewable energy consumption and financial development on $\mathrm{CO}_{2}$ emissions and economic growth in the MENA region: A panel vector autoregressive (PVAR) analysis. Renew. Energy 2019, 139, 198-213. [CrossRef]

37. Austin, K.F.; Noble, M.D.; Berndt, V.K. Drying Climates and Gendered Suffering: Links Between Drought, Food Insecurity, and Women's HIV in Less-Developed Countries. Soc. Indic. Res. 2020, 1, 1-22. [CrossRef]

38. Frongillo, E.A.; Nguyen, H.T.; Smith, M.D.; Coleman-Jensen, A. Food Insecurity Is More Strongly Associated with Poor Subjective Well-Being in More-Developed Countries than in Less-Developed Countries. J. Nutr. 2018, 149, 330-335. [CrossRef]

39. Jorgenson, A.K. Foreign Direct Investment and the Environment, the Mitigating Influence of Institutional and Civil Society Factors, and Relationships Between Industrial Pollution and Human Health. Organ. Environ. 2009, 22, 135-157. [CrossRef]

40. Zhao, Y.; Liang, C.; Zhang, X. Positive or negative externalities? Exploring the spatial spillover and industrial agglomeration threshold effects of environmental regulation on haze pollution in China. Environ. Dev. Sustain. 2020, 1-22. [CrossRef]

41. Zhao, H.; Cao, X.; Ma, T. A spatial econometric empirical research on the impact of industrial agglomeration on haze pollution in China. Air Qual. Atmos. Health 2020, 13, 1305-1312. [CrossRef]

42. Nasreen, S.; Mbarek, M.B.; Atiq-Ur-Rehman, M. Long-run causal relationship between economic growth, transport energy consumption and environmental quality in Asian countries: Evidence from heterogeneous panel methods. Energy $2020,192$. [CrossRef] 
43. Torrieri, F.; Batà, A. Spatial Multi-Criteria Decision Support System and Strategic Environmental Assessment: A Case Study. Buildings 2017, 7, 96. [CrossRef]

44. Demystifying the Environmental Kuznets Curve: Turning a Black Box into a Policy Tool. Available online: https://searchebscohost-com.libproxy.txstate.edu/login.aspx?direct=true\&db=edsjsr\&AN=edsjsr.44379189\&site=eds-live\&scope=site $($ accessed on 20 January 2021).

45. Salahuddin, M.; Gow, J.; Ozturk, I. Is the long-run relationship between economic growth, electricity consumption, carbon dioxide emissions and financial development in Gulf Cooperation Council Countries robust? Renew. Sustain. Energy Rev. 2015, 51, 317-326. [CrossRef]

46. Laila, S. Radical Hope: Transforming Sustainability. J. Sustain. Educ. 2019. Available online: http://www.susted.com/wordpress/ content/radical-hope-transforming-sustainability_2019_12/(accessed on 20 January 2021).

47. Assessment of the Impact of the Social-Economic Environment on the Development of Academic Giftedness of Russian Schoolchildren. Available online: https:/ / search-ebscohost-com.libproxy.txstate.edu/login.aspx?direct=true\&db=edselc\&AN=edselc.252.0-85086178475\&site=eds-live\&scope=site (accessed on 20 January 2021).

48. Bhattacharya, S.; Sharma, D. Do environment, social and governance performance impact credit ratings: A study from India. Int. J. Ethic Syst. 2019, 35, 466-484. [CrossRef]

49. Zhang, K.; Jiang, W.; Xu, Y.; Hou, Y.; Zhang, S.; Liu, W. Assessing the corporate green technology progress and environmental governance performance based on the panel data on industrial enterprises above designated size in Anhui Province, China. Environ. Sci. Pollut. Res. 2021, 28, 1151-1169. [CrossRef]

50. Buys, L.; Mengersen, K.; Johnson, S.; Van Buuren, N.; Chauvin, A. Creating a Sustainability Scorecard as a predictive tool for measuring the complex social, economic and environmental impacts of industries, a case study: Assessing the viability and sustainability of the dairy industry. J. Environ. Manag. 2014, 133, 184-192. [CrossRef]

51. Nogué-Algueró, B. Growth in the docks: Ports, metabolic flows and socio-environmental impacts. Sustain. Sci. 2020, 15, 11-30. [CrossRef]

52. Dörry, S.; Schulz, C. Green financing, interrupted. Potential directions for sustainable finance in Luxembourg. Local Environ. 2018, 23, 717-733. [CrossRef]

53. Growth or De-Growth?: Maybe We Don't Need to Figure That out yet. Available online: https://search-ebscohost-com.libproxy. txstate.edu/login.aspx?direct=true\&db=a9h\&AN=77617545\&site=eds-live\&scope=site (accessed on 20 January 2021).

54. Weimann, H.; Björk, J.; Håkansson, C. Experiences of the Urban Green Local Environment as a Factor for Well-Being among Adults: An Exploratory Qualitative Study in Southern Sweden. Int. J. Environ. Res. Public Health 2019, 16, 2464. [CrossRef] [PubMed]

55. Cultural Change, Religion, Subjective Well-Being, and Democracy in Latin America. Available online: https://search-ebscohostcom.libproxy.txstate.edu/login.aspx?direct=true\&db=rfh\&AN=ATLA0001744259\&site=eds-live\&scope=site (accessed on 20 January 2021).

56. Ewing, B.; Reed, A.; Galli, A.; Kitzes, J.; Wackernagel, M. Brad Ewing Anders Reed Alessandro Galli Justin Kitzes Mathis Wackernagel. In Calculation Methodology for the National Footprint Accounts, 2010th ed.; Global Footprint Network: Oakland, CA, USA, 2010.

57. Tristan, M.; Niranjan, M. Quantifying Influence in Financial Markets via Partial Correlation Network Inference. In Proceedings of the 2019 11th International Symposium on Image and Signal Processing and Analysis (ISPA), Dubrovnik, Croatia, 23-25 September 2019; pp. 306-311. [CrossRef]

58. The Birth of Hedonism: The Cyrenaic Philosophers and Pleasure as a Way of Life. Available online: https:/ / search-ebscohost-com. libproxy.txstate.edu/login.aspx?direct=true\&db=cat00022a\&AN=txi.b5379065\&site=eds-live\&scope=site (accessed on 20 January 2021).

59. Influence of Hedonic and Utilitarian Motivation on Impulse and Rational Buying Behavior in Online Shopping. Available online: https: / / search-ebscohost-com.libproxy.txstate.edu/login.aspx?direct=true\&db=edb\&AN=142851790\&site=eds-live\& scope $=$ site (accessed on 20 January 2021).

60. Grassroots Environmental Action: People's Participation in Sustainable Development. Available online: https://search-ebscohostcom.libproxy.txstate.edu/login.aspx?direct=true\&db=cat00022a\&AN=txi.b1366161\&site=eds-live\&scope=site (accessed on $20 \mathrm{Jan}-$ uary 2021).

61. Environmental Discourse and Third World Difference: Perspectives from India. Available online: https:/ /search-ebscohost-com. libproxy.txstate.edu/login.aspx?direct=true\&db=ssf\&AN=97451271\&site=eds-live\&scope=site (accessed on 20 January 2021). 